liver disease in overweight and obese patients. Liver Int 2015; 35(9):2139-46.

10. Bogdański P,ChyrekR,Pupek-MusialikD, etal. Evaluation of selected acute phase proteins in patients with metabolic syndrome. Pol Mer kur Lekarski 2006; 21(121):12-4.

11. Park SH, Kim CH, Kim DJ, et al. Diagnostic value of multiple biomarker panel for prediction of significant fibrosis in chronic hepatitis C. ClinBiochem2011;44(17-18):1396-9.

\title{
Characterization of drug poisoning among adolescents seen at the municipal hospital of Bahía Blanca, Province of Buenos Aires, Argentina
}

\author{
Ignacio Buffone, M.D. ${ }^{a}$, Mabel Dejter, M.D. ${ }^{a}$, Eliana Fortunatti, M.D. ${ }^{a}$, Florencia García Elliot, M.D. ${ }^{a}$, \\ Camila Irazabal, M.D. ${ }^{a}$, Rubén Marlia, M.D. ${ }^{a}$, Daiana Mujica, M.D. ${ }^{a}$, Marianela Parrou, M.D. ${ }^{a}$, \\ Mariana Romano, M.D. ${ }^{a}$, Gina Speciale, M.D. ${ }^{a}$ and Agostina Werneke, M.D. ${ }^{a}$
}

\begin{abstract}
Introduction. Drug poisoning among children is a frequent reason for visits to the emergency department; among adolescents, it is intentional.

Objective. To describe the characteristics of drug poisoning among adolescents admitted to the municipal hospital of Bahía Blanca.

Material and method. Descriptive study based on the review of medical records of patients aged 10-19 years seen for drug poisoning between 2012 and 2016. The following outcome measures were analyzed: age, sex, drug used, cause, clinical manifestations, and length of stay in days.

Results. Data from 72 patients were collected. Their mean age was 16 years, and the female:male ratio was 2.5:1. Anxiolytic poisoning $(30 \%)$ predominated, followed by polydrug use $(25 \%)$. Ninety-five percent of patients showed a suicidal intention; of these, $55 \%$ had a history of suicide attempt.

Conclusion. Drug poisoning was observed predominantly among girls; it is worth noting the high percentage of youth who had a history of suicide attempt.

Key words: adolescent, drug poisoning.
\end{abstract}

http:/ / dx.doi.org/10.5546/ aap.2018.eng.279

To cite: Buffone I, Dejter M, Fortunatti E, et al. Characterization of drug poisoning among adolescents seen at the municipal hospital of Bahía Blanca, Province of Buenos Aires, Argentina. Arch Argent Pediatr 2018;116(4):279-282.

a. Department of Clinical Pediatrics, Hospital Municipal de Agudos “Dr. Leónidas Lucero," Bahía Blanca, Province of Buenos Aires.

E-mail address:

Ignacio Buffone, M.D.: nacho_b89@hotmail.com

Funding: None.

Conflict of interest: None.

Received: 7-16-2017

Accepted: 12-21-2017

\section{INTRODUCTION}

In recent years, drug poisoning among adolescents has become a serious public health problem, especially in the field of pediatrics. It is the cause of up to $10 \%$ of all admissions to the intensive care unit, and the mortality rate is highly variable depending on the different health care scenarios. ${ }^{1}$

The substances involved vary greatly; antidepressants, anxiolytics, and non-steroidal anti-inflammatory drugs are the most common drug groups seen in these cases. ${ }^{2}$ Suicide attempt is the main cause of drug poisoning and one of the most concerning problems among individuals in this age group. ${ }^{3}$

At present, this is not an isolated phenomenon, but quite an everyday thing, especially among adolescents who are more prone to risk behaviors, given the changes typical of this development stage and the effect of an increasingly weakening of their social ties.

Considering the major role of this type of visits at the emergency department and because of the need to collect data to supplement local information, we decided to carry out a research study to describe the characteristics of the epidemiological patterns of drug poisoning among adolescents aged 10-19 years admitted to the emergency department of Hospital Municipal de Agudos “Dr. Leónidas Lucero" (HMALL).

\section{METHODOLOGY}

Descriptive, retrospective study based on the data collected from reviewing the medical records of patients aged 10-19 years seen at the emergency department of HMALL due to drug poisoning 
between January 1 1', 2012 and December 31 ${ }^{\text {st }}, 2016$. The study period was divided into five annual groups in order to assess the tendency of visits over time as well.

It is worth noting that HMALL of Bahía Blanca is a general acute care hospital with an emergency department that works $24 / 7$. It has a pediatric hospitalization unit with 23 beds for patients with secondary care needs. Adolescents admitted in a vulnerable condition are assessed together with the on-call psychologist to determine their risk and plan the emergency approach. If the patient is admitted to the unit, an interdisciplinary team made up of pediatricians and mental health professionals steps in to provide an assistance framework and a support network that will facilitate outpatient follow-up once the patient is discharged.

Medical record numbers for each patient were found in the hospital's electronic file system. Some of the authors collected data of interest and used them to complete specially designed worksheets.

The research protocol was approved by the hospital's Bioethics Committee, who granted access to the medical records. The data collection sheet did not include the patients' names to maintain their confidentiality.

The following outcome measures were assessed: age, sex, type of drug used, intention, history of suicide attempt, clinical manifestations at the time of admission, need for hospitalization, length of stay in days, number of admissions per year, and reasons that may have led to the event. Quantitative outcome measures were described as measures of central tendency (mean, median, and mode) and dispersion (range), whereas qualitative outcome measures, as percentage. To establish the significance when comparing certain outcome measures, the $\chi^{2}$ test and the correlation coefficient were used, considering a $p$ value $<$ 0.05 and a 95\% confidence interval (CI). The SPSS software, version 17.0, was used for data analysis.

\section{RESULTS}

Eighty patients diagnosed with drug poisoning were admitted to the emergency department in the study period. Out of all patients, 8 were excluded due to errors in diagnosis coding, so a total of 72 patients were included in the analysis.

Their median age was 16 years old, ranging from 10 to 19 years old. The mean and the mode were also 16 years.

Based on the percent distribution of patients by sex, $72 \%$ were girls (n: 52 ). The female:male ratio was 2.5:1.

Table 1 shows the frequency distribution of drug poisoning events in the 5 studied periods. A significant increase in the number of visits was observed in 2015; similar numbers were observed in the rest of the years. The differences were not statistically significant ( $p=0.1,95 \%$ CI: 0.075-0.42).

In relation to the frequency of use by drug group, anxiolytics predominated and were used by 22 of the 72 patients, whereas polydrug use was observed in 18 cases (Table 2).

Regarding the clinical presentation at the time of the visit, little more than half of patients (n: 39) were asymptomatic, whereas 24 had neurological symptoms (lethargy, dizziness, depression of consciousness, sleep tendency); 7 , gastrointestinal symptoms (vomiting, abdominal pain), and only 2, cardiovascular symptoms (tachycardia, hypotension).

Out of all patients, 95\% (n: 68) referred a suicidal intention. Of them, 55\% had a history of suicide attempt. When compared by age group, adolescents older than 15 years showed a higher percentage of suicidal attempt as a cause of drug poisoning ( $p=0.037,95 \%$ CI: $0.034-0.041)$ and a higher proportion of history of suicidal attempt ( $p=0.034,95 \%$ CI: 0.032-0.04). No significant differences were observed by sex $(p=0.798,95 \%$ CI: 0.798-0.806).

TABLE 1. Frequency distribution by study period

\begin{tabular}{lccc}
\hline Period & \multicolumn{3}{c}{ Visits by sex } \\
& Female (n) & Male (n) & Total (n\%) \\
\hline 2012 & 8 & 5 & $13(18 \%)$ \\
2013 & 5 & 6 & $11(15 \%)$ \\
2014 & 14 & 1 & $15(21 \%)$ \\
2015 & 17 & 5 & $22(31 \%)$ \\
2016 & 8 & 3 & $11(15 \%)$ \\
\hline
\end{tabular}

TABLE 2. Frequency distribution by drug group involved in drug poisoning, expressed in percentage

\begin{tabular}{lc} 
Type of drug & Frequency of use (n $\%)$ \\
\hline Anxiolytics & $22(30 \%)$ \\
Analgesics & $10(14 \%)$ \\
Antihypertensive drugs & $2(3 \%)$ \\
Allergy medicines & $3(4 \%)$ \\
Stimulant drugs & $2(3 \%)$ \\
Antidepressants & $2(3 \%)$ \\
Antibiotics & $1(1.5 \%)$ \\
Medication & $18(25 \%)$ \\
Unknown & $7(9.5 \%)$ \\
Others & $5(7 \%)$ \\
\hline
\end{tabular}


Family conflicts were the most important reason given when asked for the reason to do it $(49 \%)$. Other reasons were school conflicts $(10 \%)$ and couple conflicts (9\%).

Based on the results, $42 \%$ of patients (N: 30$)$ required admission to the pediatric care unit or the clinical care unit, depending on the patient's age, and the length of stay was 2.5 days in average; no significant differences were observed between sexes ( $p=0.054,95 \%$ CI: 0.03-1.98). Only 1 patient required hospitalization in the intensive care unit and achieved an adequate clinical course. No deaths were recorded.

\section{DISCUSSION}

Visits due to drug poisoning were mostly related to the female sex, which was consistent with what had been observed in other studies that found a female:male ratio of $3: 1 .^{4,5}$ In terms of age, most patients were late adolescents, which was in accordance with prior publications that pointed out that the 15-19-year-old population predominated. ${ }^{6,7}$

Psychotropic drugs were the most commonly used ones; among these, anxiolytics prevailed. Reports have been uniform in pointing out that these are the most commonly used drugs in the studied situation. ${ }^{4,6}$

It is important to note the large percentage of patients who stated that they had taken the drugs with a suicidal intention. In a study conducted at Hospital Universitario Ramón y Cajal in Madrid, $83.8 \%$ of poisonings were voluntary. ${ }^{8}$ Likewise, a study carried out between 2009 and 2011 at a hospital in Turkey found a $92 \%$ of voluntary poisonings. ${ }^{9}$

Accidental poisoning events usually occur during childhood, whereas in the case of adolescents, they mostly do it intentionally. ${ }^{10}$

The most interesting piece of information is the large number of patients who had a history of suicide attempt, either with drugs or by other means. The rate of repeat suicide attempt among adolescents is approximately $6-14 \%$ in the first year of follow-up according to previous studies. ${ }^{11}$ Our study showed higher rates, similar to those observed in regional studies, such as the study conducted in the city of Córdoba in 2006, which found that $68.8 \%$ of youth had had a prior attempt. ${ }^{12}$ Similarly, in a study carried out in the city of Santiago de Chile in 2012, repeat attempts accounted for $51 \%$ of the cases. ${ }^{13}$

It has been observed that the frequency of poisonings does not follow an increasing pattern over the years, given that results were varied when each study period was analyzed. This is probably due to errors in diagnosis coding, which may have left cases of drug poisoning out of the study.

The limitations of this study are its descriptive and retrospective nature and the small case series. However, considering the population characteristics of the city of Bahía Blanca, it could be stated that the number of adolescents who had a drug poisoning event was substantial.

Future prospective studies on this topic using qualitative methods are required so as to further investigate the aspects related to adolescents.

\section{CONCLUSION}

In this study, it is worth noting the prevalence of female patients attending the emergency department due to drug poisoning. Anxiolytics were the most commonly used drugs, and an important percentage of patients had a history of prior drug poisonings. $\mathbf{n}$

\section{REFERENCES}

1. Fernández-BarocioF,Sánchez-VillegasMCS.Epidemiología delas intoxicaciones en el servicio de urgencias pediátricas de un hospital de tercer nivel. Reporte de cinco años. Archivos de Medicina de Urgenc de Méx 2013; 5(1):18-24.

2. Programa Nacional de Salud Integral en la Adolescencia. Situación de la salud de las y los adolescentes en la Argentina. Buenos Aires: Ministerio de Salud - UNICEF; 2016. [Accessed on: December 27th, 2017$]$. Available at: http: / / www.msal.gob.ar/images / stories / bes / graficos /0000000872cnt-linea-base-adolescencia-2016.pdf.

3. Galvis Pérez A, Ospina Díaz JM, Manrique Abril FG. Caracterización de la intoxicación exógena en niños y adolescentes en Sogamoso, Boyacá durante el período de 2010 a 2013. Medicas UIS 2014; 27(1):9-16.

4. Dessauer B, Ortiz P, Hinostroza T, et al. Intento de suicidio vía ingesta de fármacos en niños. Rev Chil Pediatr 2011; 82(1):42-8.

5. Zöhre E, Ayrik C, Bozkurt S, et al. Retrospective Analysis of Poisoning Cases Admitted to the Emergency Medicine. Arch Iran Med 2015; 18(2):117-22.

6. Prada DB, Evangelista M, Piola JC. Tentativas de suicidio con tóxicos en adolescentes en Rosario, Argentina. 19901998. Brazilian Pediatric News 2002; 4(3):1-11.

7. Pringle K, Caupp S, Shi J, et al. Analysis of intentional drug poisonings using Ohio Poison Control Center Data, 20022014. Clin Toxicol (Phila) 2017; 55(7):652-8.

8. Medina González L, Fuentes Ferrer ME, Suárez Llanos JP, Arranz Peña MI, et al. Epidemiología de las intoxicaciones medicamentosasduranteun añoen el Hospital Universitario Ramón y Cajal. Rev Clin Esp 2008; 208(9):432-6.

9. Kara H, Bayir A, Degirmenci S, et al. Causes of poisoning in patients evaluated in a hospital emergency department in Konya, Turkey. J Pak Med Assoc 2014;64(9):1042-8.

10. Cuesta-Revé D. Aspectos epidemiológicos del suicidio en adolescentes. Rev Mex Pediatr 2017; 84(2):72-7.

11. Poblete R, Morell I, Cabrera D, et al. Intoxicación medicamentosa voluntaria: un paciente, dos problemas. Rev Chil Med Intensiva 2008; 23(2):85-93. 
12. Bella M, Fernández R, Willington JM. Identificación de factores de riesgo en intentos de suicidio en niños y adolescentes. Rev Argent Salud Pública 2010; 1(3):24-9.
13. Inzunza C, Navia F, Catalán $P$, et al. Conducta suicida en niños y adolescentes ingresados en un hospital general. Análisis descriptivo. Rev Med Chile 2012; 140(6): 751-62. 